\title{
Research on the Evaluation Mechanism of Independent Colleges Jia YANG
}

\author{
Zhuhai College of Jilin University, Zhuhai, China
}

\begin{abstract}
Keywords: Independent College; Teaching Quality; Assessment Mechanism.
\end{abstract}
\begin{abstract}
The lack of systemic evaluation mechanism in independent colleges, the singleness of assessment participants, and the lack of interaction of assessment mechanisms have limited the effectiveness of assessment mechanisms. This paper analyzes the prominent problems in the evaluation mechanism of independent colleges, introduces the basic principles of objectivity, operability, relevance, orientation, and relevance, and puts forward some suggestions for improving the evaluation mechanism of independent colleges to achieve the maximum effect of the assessment mechanism within the school.
\end{abstract}

\section{Introduction}

Independent colleges have their own uniqueness. The resources advantages of public universities are not available in private universities. Independent colleges can absorb more social funds and can attract more social forces to college construction. Even more, the university that independent colleges are affiliated with had a long history and profound cultural heritage, so independent colleges have more advantages in self-evaluation. Independent colleges should make full use of their advantages to further enhance the scientificness and effectiveness of internal evaluation and seek better development opportunities for independent colleges.

\section{The Prominent Problems of the Evaluation Mechanism in Independent Colleges}

At present, there is lack of characteristics in the evaluation mechanism of independent colleges in our country. The following outstanding problems have restricted the effectiveness of the evaluation mechanism within the school and, to a certain extent, have restricted the further optimization and promotion of the quality of education and teaching in independent colleges.

\subsection{Lack of systemic intra-school assessment mechanism}

The intra-school assessment mechanism is a systematic project. The construction of assessment mechanisms in many independent institutions is not systematic, and it is impossible to establish a systematic assessment mechanism based on the objectives and characteristics of personnel training in independent institutions. As a result, the assessment mechanism in the school is not perfect and cannot form an organic whole, which weakens the effective function of the assessment mechanism in the school as a whole.

\subsection{A single participant in school assessment work}

At present, the main participants of independent school assessment work are assessment experts and lack of the participation of front-line teachers [1]. The lack of evaluation of the main line teachers leads to the lack of operability in the construction of the assessment mechanism within the school, and evaluation experts often pay too much attention to the theoretical level assessment when implementing assessments. Without practical guidance, it is difficult to exert the guiding role of internal assessment in the education and teaching of independent institutions.

\subsection{Lack of interactivity in Intra-school assessment mechanism}

The links in the various aspects of the evaluation mechanism of independent schools, the indicators, and the participants involved in the assessment should be organically integrated. However, the evaluation mechanism for independent schools is severely fragmented. The lack of effective interaction has led to an imbalance in the evaluation of various courses. It has even led to 
the emergence of boycotts among different subjects in education and teaching, and has affected the overall effect of the evaluation mechanism in independent schools.

\section{Basic Principles for the Construction of the Evaluation Mechanism in Independent Colleges}

An important factor that caused the above-mentioned problems in independent colleges is that the construction of evaluation mechanisms is decoupled from its own development laws. Therefore, the construction of the independent school assessment mechanism should respect the objective law and abide by the following basic principles to improve the effectiveness and scientific nature of the evaluation mechanism for independent schools.

\subsection{Principle of objectivity}

The construction of evaluation mechanisms for independent colleges must follow the principle of objectivity, based on the general laws of higher education, on the training objectives and characteristics of universities in independent colleges. Various factors and links that restrict the improvement of education and teaching quality in independent colleges should be thoroughly analyzed, so that the assessment mechanism in schools is continuously improved based on the existing problems.

\subsection{Operability principle}

The purpose of establishing an independent college assessment mechanism is to further promote the self-development of colleges and improve the quality of school education and teaching. Therefore, the construction of independent institutions' assessment mechanism should follow the principle of operability, the assessment criteria should be concise, the evaluation dimensions should be close to the actual situation of independent colleges, and the evaluation project should be more objective and less subjective, so that the evaluation is simple and easy.

\subsection{Suitability principle}

The construction of independent institutions' assessment mechanism should follow the principle of appropriateness. First of all, it is necessary to reflect the educational characteristics of independent colleges to distinguish them from non-governmental ones, to demonstrate the characteristics of independent colleges and universities, and to display their own advantages; Secondly, we must reflect the characteristics of the college itself. Although there is a commonality in the evaluation mechanism among independent colleges, the differences among independent colleges are objective. They need to be appropriate for each independent college and demonstrate the personality and characteristics of the school.

\subsection{Guiding principle}

With the development of the times, the training objectives and plans of independent colleges and universities are constantly adjusted. The construction of independent institutions' assessment mechanisms should follow the guiding principles, according to the development of the times and the society's demand for personnel training in independent colleges. It is necessary to timely adjust the assessment mechanism in schools to adapt them to the needs of the times and talents of the society.

\subsection{The principle of full staff}

Independent colleges and universities are an organic whole. To improve the quality of personnel training in independent colleges and universities, we must follow the principle of full membership and stimulate the initiative for full participation of independent colleges. In this way, a high degree of coordination among various departments and different subjects has been created, and they have consciously participated in the improvement of the quality of education and teaching in institutions of higher learning, and promoted the consciousness of self-consciousness and coordination of internal assessment. 


\section{Some Suggestions on the Improvement of the Evaluation Mechanism in Independent Colleges}

In order to further improve the effectiveness of the construction of independent school assessment mechanisms, the construction of evaluation mechanisms for independent colleges should focus on the following aspects.

\subsection{Improve teaching quality assessment system}

Quality is the lifeline for the survival of any institution. Therefore, the improvement of the evaluation mechanism for independent institutions needs to improve the existing teaching quality assessment system so as to exert the guiding role of the evaluation within the school to the quality of teaching.

\subsubsection{Extend the main body of evaluation}

The evaluation of teaching quality in independent colleges and universities shall break the current status of the subject of single evaluation and organically combine teacher evaluation with student evaluation. The development of the assessment subject can not only examine the teaching from the perspective of the teacher, but also help each other to enrich the assessment perspective, inspire students to participate in the evaluation initiative, and tap students' potential.

\subsubsection{Improve teacher evaluation}

At present, the evaluation of teachers in independent colleges focuses on the evaluation of teaching effects and neglects the evaluation of teachers' personal qualities. In view of this situation, we must organically combine the evaluation of teaching effectiveness with the individual evaluation of teachers, so as to fully optimize the quality of teachers in independent colleges and promote the sustainable development of teachers, and provide teacher with protection for the improvement of teaching quality in independent colleges and universities.

\subsubsection{Improve the incentive mechanism}

The perfection of the evaluation mechanism for independent colleges and universities also needs to combine the teacher evaluation with the college evaluation organically [2]. Through the improvement of the college's incentive mechanism, the evaluation of the teacher's teaching quality is incorporated into the school evaluation. Through the incentive and effective supervision of the college, the potential of the teacher is fully tapped, to strengthen teachers' awareness of quality improvement.

\subsubsection{Improve assessment agencies}

Independent colleges and universities shall further improve the assessment institutions within the school according to the needs of the assessment within the school. In the process of expanding the assessment subject, it is necessary to further strengthen the sense of responsibility, implement the assessment of the participants' responsibilities in the evaluation, and enhance the scientific evaluation, in strict accordance with the assessment [3]. Rules, standards, etc., standardize assessment behavior.

\subsection{Improve teaching quality assessment methods}

The improvement of the evaluation mechanism for independent schools also needs further optimization of teaching quality assessment methods. Starting from the actual situation of independent colleges and universities, it not only respects the general rules of evaluation within the school, but also reflects the characteristics of independent colleges and universities themselves.

\subsubsection{Analytic Hierarchy Process}

Analytic Hierarchy Process (AHP) is an analysis method for calculating the indicators of teaching quality evaluation in independent colleges. This method has its own advantages and can simplify relatively complex issues. The method of processing is to layer the problem, which can effectively solve the problem of inconsistent thinking in the evaluation process and maintain a high degree of consistency in quality assessment. 


\subsubsection{Fuzzy Comprehensive Evaluation Method}

The fuzzy comprehensive evaluation method refers to an analysis method that deals with various elements and data in the quality evaluation process, including data collection, aggregation, and classification. This method can effectively deal with complex assessments, integrate multiple factors, consider multiple levels, and its defect is that it cannot effectively divide boundaries.

The choice of teaching quality assessment methods in independent colleges and universities has to be different from time to time, reflecting flexibility, and combining AHP with fuzzy comprehensive evaluation methods to achieve both advantages and make up for the lack of both.

\subsection{Improve quality assessment feedback mechanism}

The assessment mechanism of independent colleges also needs to further improve the quality assessment feedback mechanism and improve the effectiveness of the evaluation mechanism within the school through timely and accurate feedback.

\subsubsection{Improve assessment feedback timeliness}

The independent college quality assessment feedback should focus on timeliness, grasping the timing of assessment feedback, enable various departments and relevant personnel to grasp the assessment results in time, and then serve the independent colleges and universities to improve teaching quality, to achieve the maximum effect of the assessment mechanism within the school.

\subsubsection{Improve assessment feedback accuracy}

Only accurate quality assessment information can play its own assessment value, so independent colleges should pay attention to improving the accuracy of assessment feedback information, truly reflect the level of teaching quality of independent colleges and universities, can play the guiding role in the evaluation of quality improvement, and timely adjustment of educational and teaching behavior.

\section{Conclusion}

In short, the independent college assessment mechanism is of great significance to improve the quality of teaching and the quality of running schools. Independent colleges and universities shall, based on the significance of the assessment within the school, examine the current situation of the evaluation mechanism within the school and follow the general principles of the construction of the assessment mechanism within the school. The internal evaluation mechanism of the school should be improved at different levels, and the relationship between individuals and the whole, tradition and innovation, process and results, qualitative and quantitative should be well handled, so as to achieve the maximum effect of the assessment mechanism within the school.

\section{References}

[1] Xuezhen LI, Hejiang WANG. Intermediary evaluation mechanism: external guarantee of the quality of independent college education [J]. Educational Theory and Practice, 2010 (27): 14-16. (In Chinese)

[2] Jiehui SHI. Research and analysis on the evaluation of teaching quality of independent college [D]. Hebei University of Science and Technology, 2014. (In Chinese)

[3] Huiya FENG. Research on the Operational Mechanism of Independent Colleges from the Perspective of Government Management [D]. South China University of Technology, 2012. (In Chinese) 